\title{
The High-Scope Curriculum Support for Early Childhood Development -Take Active Learning in Young Children as an Example
}

\author{
Zhiqi Cai \\ Faculty of Education, Yunnan Normal University, KunMing,650504, China \\ Corresponding author's Email: 1186840490@qq.com
}

\begin{abstract}
This paper introduces the origin of the High-Scope curriculum from the beginning of the later development of the curriculum model. Then, it introduces what is High-Scope curriculum's Key Development Indicators and 'learning round', and how they support the development of the core of active participatory learning. And from the social progress and children's long term development introduce the advantages of the curriculum. And how do the primary theoretical basis and the operability of the curriculum for teachers and parents as well as the comprehensiveness of the curriculum support children's active learning ability? Finally, the article introduces under the background of implementation of 'double reduction' policy, how to integrate High-Scope curriculum in China's preschool education. In the end, based on the theories of Piaget and Vygotsky and other scholars in the early stage, the High-Scope curriculum aims to solve the educational problems of poor children, taking active learning as the core, and carrying out the curriculum through 'learning round'. All of these support the High-Scope curriculum aimed at children's active learning. These provide opportunities for the implementation of the High-Scope curriculum under the background of China's double reduction policy.
\end{abstract}

Keywords: High-Scope curriculum, active learning

\section{INTRODUCTION}

The High-Scope curriculum represents a curriculum model of preschool education. From the beginning, the article introduces what the High-Scope curriculum is? What are the benefits of the High-Scope curriculum? How does the High-Scope curriculum work? What is a High-Scope curriculum, introduces the origin of curriculum, and the significance of the birth of the curriculum. Then introduces it later developed into a curriculum covering eight areas of early childhood development. And from the course support- "learning round"— the core concept of High-Scope learning actively, participating in supportive Adult — child interaction, creating a challenging learning environment, establishing a solid daily routine, carrying out a continuous evaluation to make a lesson plan, respectively introducing the content of each plate, elaborating how they support children's active learning ability as well as my understanding of these course plate content. Next, what are the strengths of the course and how does the course work? First, the benefits introduced from the economic benefits and children's long-term progress. Then, the benefit is analyzed from the primary theoretical basis of Piaget, and Vygotsky. The passage also analyzes the operability of the curriculum for teachers and parents, elaborating with restricted operating steps. And passage introduces the comprehensiveness of the curriculum by taking five active learning elements in the curriculum to solve the problem of lacking functional learning in kindergarten teaching in China as an example. Finally, last paragraph presents what double reduction" policy is and how to implement the High-Scope curriculum under the background of China's "double reduction" policy. Young children exposed to High-Scope curriculum having active learning ability can enable them to explore the world independently and construct their own thinking to understand society. From a young age, children have strong independent learning ability, which can lay a foundation for learning at school age and keep an enthusiastic attitude towards learning. Under the exam-oriented education system in China, the High-Scope curriculum allows children to have the 
ability to find out independently, which can reduce some of their learning burden at school age.

\section{WHAT IS HIGH-SCOPE}

\subsection{The aim and KDIs of High-Scope}

The High-Scope curriculum starting in the 1960s, is a support to the Perry Preschool Program study. It can be traced to the High-Scope Perry Preschool Program. To solve the educational problem of preschool education of poor children in America. David P. Weikart initiated the Perry Preschool Program study [1]. High-Scope means helping children have high aspirations and a broad scope of interest. Despite that, the High-Scope curriculum is also a model that supports efforts to learn actively, learning from the activity and key development indicators (KDIs). There are eight areas of the High-Scope curriculum, including Approaches to Learning, Social and Emotional Development,Physical Development and Health, Language, Literacy, and Communication, Mathematics, Creative Arts, Science and Technology, Social Studies, all of which have their key development indicators. Each of them needs to be evaluated through specific criteria.

\subsection{Guiding principle - 'Tearning round'}

To get all the KDIs and improve their levels, the High-Scope curriculum designs the 'learning round' to be the guiding principle. In the middle of the 'learning round' is the core concept of High-Scope learning actively. There are four sectors representing four responsibilities that teachers interact with children: Participating in supportive Adult-child interaction, creating a challenging learning environment, establishing a dependable daily routine, carrying out a continuous evaluation to make a lesson plan[2].

Learning actively is the basic principle that children can build or construct their knowledge of the world by themselves [3]. To do it, the adult should supply a large amount of actionable and fun materials to the child. They have to support 'scaffold' to children finish their exploration and create the new challenge under their zone of proximal development (ZPD). For children, they can choose the people and the materials they plan on getting back together with them. They can explore the materials and communicate or share with others what they discover or how they change their mind to start the original plan. The core of adult-child interaction is sharing the right to control. It has four strategies to teach adults how to share. Making a challenging learning environment: High-Scope offers guidelines about how to design the area, how to choose the materials and how to store the materials. Establishing a robust daily routine: Despite High-Scope has different types of curriculum, time to plan (10-15minute), time to work (45-60minute), time to clean up (about 10minute), time to review (10-15minute) is always in this order. Carrying out the continuous evaluation: High-Scope has two systems to evaluate curriculum, one is Preschool Child Observation Record (COR Advantage to evaluate children's progress. Another is the Preschool Program Quality Assessment (PQA) to evaluate the preschool educational institution.

\subsection{The core of High-Scope curriculum- learning actively}

From my perspective, learning ability is the most essential goal of the High-Scope curriculum. We can see the importance of the initiative as the first key development indicator in the area of approaches to learning. Learning actively is running through the High-Scope curriculum. Specifically, key development indicators (KDIs) are specific criteria that help children approach it. Adults can use these indicators to assist children improve. According to the scoring guide of COR Advantage, in the area of approaches to learning, there are 8 levels of the second KDI that utilize materials to solve problems. The lowest level (0level) is young children turn their eyes, head, or hands to the person or object they desire. The highest level (7level) is immature children coordinate multiple resources (materials and people) to solve complex problems related to materials. The adults have to make a lesson plan to support the child's progress from level 0 to level 7[4]. Through this, children can develop their ability to learn actively by using materials to address the problems.

\subsection{The concrete content of High-Scope-'learning round'}

The 'learning round' is the concrete support of realizing a goal. The sector is creating a challenging learning environment that supports objective conditions. The adults create the environment and choose the materials as well as arrange them to assist children to explore. The sector that participates in supportive adult-child interaction is the support of subjective conditions. Adults can follow the strategies to engage the children's exploration to communicate with children and to encourage children to overcome the difficulty. Support children learning actively. The sector establishing a solid daily routine guaranteed that the High-Scope curriculum goes on wheels. It can ensure that children's exploration is in order. And adults can select from KDIs to make a lesson plan. Besides, it is more convenient for adults to control and record whether children achieve the selected KDIs. Also, establishing a dependable daily routine is helpful to the novice teachers to get started with High-Scope, since there is a fixed order that starts with time to plan and 
ends in time to review. And all the parts have the recommended time for novice teachers to arrange. The sector carrying out continuous evaluation is an inspection of the High-Scope curriculum. The two evaluation systems, COR Advantage and PQA, are direct and efficient recording systems to inspect whether a High-Scope curriculum is available to the child and the preschool educational institution. They are stored updated according to the development of time and children which can guarantee two systems' validity.

\subsection{The metaphor of High-Scope}

Imagine that High-Scope curriculum as a car. Learning actively is a steering wheel, for the reason that it has to keep the car in the direction where children can develop the ability to learn actively. The KDIs are components and parts of the engine, which means they are the power to hold the car moving. They are the motivation to stimulate children to strive for further improvement. In this part, adults have to use the 'scaffold' to support children to improve. To exemplify, in the area of mathematics, children might use the word 'more or less ' when they are comparing numbers. According to the scoring guide of COR Advantage, these children are at level 1. Under these circumstances, adults can determine the number when children are comparing items. This way is called 'scaffold learning', which can help the children to have the number sense to improve to level 3 (children can count the object under 10 with one-to-one correspondence.). The four sectors in the 'learning round 'are four tires of the car. Participating in supportive adult-child interaction, creating a challenging learning environment, establishing a solid daily routine, carrying out a continuous evaluation, every single one of them is needed to guarantee the implementation of the High-Scope curriculum.

\section{WHY HIGH-SCOPE BENEFITS?}

\subsection{The economic benefits and personal long-term development of the High-Scope curriculum}

According to the research of High-Scope curriculum study in 2005, American scholars, Lawrence J.Schweinhart and Jeanne Montie found out if a high-quality education is received at an early age, it will have a profound impact on one's life and then influence on society. In the analysis of the costs and benefits of getting a preschool education in the High-Scope curriculum model, they discover that adjusted for inflation and so on, for every dollar spent on preschool education of poor children, $\$ 17.07$ was returned. And $\$ 12.90$ belongs to taxpayers, $\$ 4.17$ belongs to the children themselves. The Nobel economics laureate James J.Heckman with his colleagues confirmed the findings after re-analyzing the data in the High-Scope study. Also, they made the point for women, the High-Scope Perry Preschool Program had a beneficial impact in terms of increased educational achievement, employment rates, economic gains in adulthood, and lower arrest rates. For men, the High-Scope Perry Preschool Program had a positive impact on lower arrest rates, reduced incarceration, increased earnings at age 27 , increased employment at the age of 40 , and other economic gains. Plus, they also found that compared to the children who participated in other preschool curriculum, children who took part in the High-Scope curriculum model would be most influenced by preschool education when they were after 40 years of age [5].

\subsection{Early theoretical support of children's active learning ability in High-Scope curriculum}

The High-Scope curriculum used the term 'active participatory learning' to stress the importance that children are constructors of knowledge. Hohmann, Weikart\&Epstein(2008) thought, 'Active participatory learning is a process in which children actively participate in learning and construct new understanding by manipulating material and interacting with other people, ideas, and events. No one can experience the objective world or construct knowledge for the child. The child must do this alone. [6] Affected by the educational theory and thought of Piaget, and Vygotsky, the High-Scope curriculum emphasizes children actively gain experience. In the book <Educational science and child psychology $>$, though Piaget thought imparting education is beneficial to children in a way, he stressed that education should stimulate children to actively and independently practice and explore [7]. And Vygotsky, his most well-known theory, 'zone of proximal development ' (ZPD). It is a distance between a child who can complete tasks independently and with the help of an adult or a peer of superior ability to complete the tasks. This area is called ZPD. So, adults have to create a task slightly above the child's level, and it requires the child to learn and experience actively with maximum initiative, to get into the higher level of learning. Based on these theories, the High-Scope curriculum puts active learning in the central area. Children have to construct the experience by themselves, through operating materials and interacting with adults and the surrounding environment.

\subsection{Accessible for adults to use}

From my point of view, the High-Scope curriculum is the most authoritative for supporters to learn to observe and record children's active learning ability. The High-Scope curriculum creates a complete system to help supporters to evaluate children's active learning 
ability. Also, it gives supporters concrete steps to record children's behavior of dynamic learning. The first step is using the scoring guide of COR Advantage to find sentences that describe children's active learning development. The second step is according to these descriptions, supporters record anecdotes related to active learning in table A (initiative and planning) in the anecdote handbook. Finally, they follow the scoring guide of COR Advantage to determine children's levels of active learning progress. For parents, COR Advantage of High-Scope curriculum is the easiest system for them to observe and record children's active learning ability in a systematic way. Parents fill 'home report form' from observing children's anecdotes of functional learning. Before this, parents need to read the 'family manual' to understand initiative learning as children eager to learn and implement their ideas. And they have to focus on how children learn rather than what they learn. Then it will be very easy for them to observe and record children's initiative learning. Plus, through this, supporters were interested to know how children's active learning develops at home [8].

\subsection{The comprehensiveness in High-Scope curriculum}

In addition to being easy for adults to use, the High-Scope curriculum has another advantage is the comprehensiveness of the curriculum. For example, the High-Scope curriculum summarized five basic elements of active learning, including selection, materials, manipulation, children' s language and thinking, and adult support [9]. To be honest, these five elements can exactly solve the problem of the realistic representation of active learning deficiency in kindergarten teaching in our country. According to the Chinese scholar Zhang $\mathrm{Yu}$ in the article 'Active Learning: The Value Pursuit of Kindergarten teaching', it is noted that there are three aspects of this problem. Firstly, lack of internal motivation to initiate learning activities. Children' $s$ internal learning motivation comes from their interests. Most kindergartens in our country don' t provide or update a wealth of material to stimulate or sustain young children' $s$ interest in autonomous exploration. And most teachers in kindergartens hope that children can learn step by step in their planned courses, so a lot of children lose interest in autonomous exploration. The High-Scope curriculum attached great importance to offer a wide range of materials available to children in a variety of ways. A wide range of materials including daily practice materials; Natural and available materials; tools; messy, sticky, soft, wet, spongy materials; heavy, large materials; easy to use materials, all can stimulate children's interest in active learning. They also focus on updating these materials to sustain children's interest in active learning. Plus, the High-Scope curriculum gives the choice back to the child. Children choose what they want to do and actively participate in activities based on their interests and intentions. Secondly, lack of hands-on and communicative learning. In the High-Scope curriculum, adults encourage children to manipulate objects freely and they encourage children to talk about their experiences or describe what they are doing with their words. Last but not least, lack of problem-oriented deep learning. In the High-Scope curriculum, it gives children lots of freedom to choose the thing they want to do. Freedom doesn't mean no purpose. One of the rudimentary elements of adult support is that adults have to build partnerships with children, keep up with children's thoughts and interests. And they have to observe and understand children's intentions. When children deviate from intention, adults should allow children to make mistakes and use equal dialogue to encourage the children to think.

\subsection{The implement of High-Scope curriculum in China under the double reduction policy}

The double reduction policy is a set of guidelines that Chinese authorities introduce to ease the burden of excessive homework and off-campus tutoring for students undergoing compulsory education. The guide was from a press conference held by the Ministry of Education. At the end of the guideline, it adds: "While reducing the number of students in compulsory education, local governments should also make overall plans for off-campus training for preschoolers aged 3 to 6 and regular senior high school students. Online training for preschoolers is not allowed. It is strictly forbidden to carry out offline subject training (including foreign language) for preschool children in the name of the preschool class, kindergarten, and primary school bridging class, thinking training class, etc. No more approval will be given to new out-of-school training institutions for preschoolers and out-of-school training in disciplines for ordinary senior high school students. "[10] So, as a preschool education model, the High-Scope curriculum in China faces the problem of being a preschool institution, how to promote it under the background of this new guidance. This is just my point of view on this issue. The High-Scope curriculum can't be organized as a training institution or extracurricular institution but as a teaching model in kindergartens, and the practice of localization of High-Scope curriculum should be performed. Let the High-Scope curriculum according to regional conditions, and promote the development of children's independent learning ability.

\section{CONCLUSION}

As a project dedicated to solving the preschool education problems of poor children in the United States, the effectiveness and importance of High-Scope curriculum is very obvious when it is supported by the 
theories of Piaget and Vygotsky and other scholars in the early stage, as well as the research results from the long-term development of children and social and economic benefits. 'Learning round' is the concrete support of the curriculum, and active learning is the core of the curriculum. The comprehensiveness of the dynamic learning element in the High-Scope curriculum is the performance of the core of active learning throughout the whole High-Scope curriculum mode. Participating in supportive Adult - child interaction, creating a challenging learning environment, expressing a solid daily routine, and carrying out a continuous evaluation to make a lesson plan are the basic principles that support the development of children's active learning. And every principle has specific and clear guidelines. It makes it very easy for beginners to master and get started. For Approaches to Learning, Social and Emotional Development, Physical Development and Health, Language, Literacy, and Communication, Mathematics, Creative these eight areas, complete and clear key development indicators (KDIs) are set. Each field has different evaluation methods and based on this, a complete and systematic evaluation system (COR Advantage) is designed. Under the background of the "double reduction" policy in China, it provides an opportunity for High-Scope curriculum to be formally implemented in domestic kindergartens as a preschool education model.

\section{REFERENCES}

[1] Written by HighScope Educational Research Foundation. Translated by Huo Liyan.etc. Preschool Child Observation Record (COR Advantage) [M].Beijing:Education Science Publishing House,2018:Preface to the translator of the series 001

[2] Xia Jingwei. Analysis of High/Scope curriculum Model[J].Education to observe (the second half of the month).2016(07):27-30

[3] Written by Beth Marshall. Shannon Lockhart. Moya Fewson; Translated by Sha Li.etc. Lesson Plans for the First 30 Days: Getting started with HighScope, 3rd Edition[M]. Education Science Publishing House, 2018:2

[4] Written by HighScope Educational Research Foundation. Translated by Huo Liyan.etc. Preschool Child Observation Record (COR Advantage $\quad[\mathrm{M}]$.Beijing:Education Science Publishing House, 2018:022:024

[5] Written by Ann S. Epstein. Translated by Huo Liyan.etc. Approaches to Learning[M].2018: Preface to the translator of the series 002
[6] HohamnM,Weikart, D. \&Epstein.A .S.Educating Young Children: Active Learning Practices for Preschool and Child Care Programme[M].Ypsilanti,MJ:High/Scope Press,2008:17.

[7] Shen Zhenglan. A study on High-Scope curriculum in American preschool education[D].Fujian Normal University.2017(09):41

[8] Written by HighScope Educational Research Foundation. Translated by Huo Liyan.etc. Preschool Child Observation Record (COR Advantage) [M].Beijing:Education Science Publishing House,2018:142:169

[9] Monica Wiltshire. Understanding the High/Scope approach: early years education in practice [M].London: Routledge, 2012:39-41.

[10]Ministry of Education of the People's Republic of China http://www.moe.gov.cn/jyb_xxgk/moe_1777/moe_ 1778/202107/t20210724_546576.html 